\title{
Erratum to: Molecular variability elicits a tunable switch with discrete neuromodulatory response phenotypes
}

\author{
Warren D. Anderson ${ }^{1,2,3}$ • Hirenkumar K. Makadia ${ }^{1,3}$ • \\ Rajanikanth Vadigepalli ${ }^{1,2,3}$
}

Published online: 21 January 2016

(C) Springer Science+Business Media New York 2016

\section{Erratum to: J Comput Neurosci}

DOI 10.1007/s10827-015-0584-2

In the initial online publication of the manuscript, the Supplementary Figures S1 through S16 were not made available online. We regret this production error and have now made these online Supplementary files available.

Rajanikanth Vadigepalli

Rajanikanth.Vadigepalli@jefferson.edu

1 Daniel Baugh Institute for Functional Genomics and Computational Biology, Thomas Jefferson University, 1020 Locust St, Philadelphia, PA 19107, USA

2 Graduate program in Neuroscience, Thomas Jefferson University, 1020 Locust St, Philadelphia,

PA 19107, USA

3 Department of Pathology, Anatomy, and Cell Biology, Sidney Kimmel Medical College, Thomas Jefferson University, 1020 Locust St, Philadelphia, PA 19107, USA 